\title{
Effect of high ambient room temperatures on metabolic rate and performance of laying hens in two housing systems
}

\author{
E. H. Ketelaars, H. Brandsma, W. van der Hel, J. M. van der Linden, \\ M. W. A. Verstegen and A. J. Wilbrink
}

Agricultural University, Department of Animal Husbandry, Marijkeweg 40, 6709 PG Wageningen, the Netherlands

Received 7 November 1984; accepted 26 April 1985

Key-words: room temperature, metabolic rate, performance, hen, housing

\section{Summary}

Laying hens of a medium type, housed in a cage or on a wire floor system, were exposed to changing environmental temperatures from $20^{\circ} \mathrm{C}$ to $32{ }^{\circ} \mathrm{C}$ and back to $20^{\circ} \mathrm{C}$ within 30 days. Egg production, egg weight, egg shell percentage, body weight and feed consumption dropped significantly in both systems. The effect however was much more pronounced in the cage system. The same pattern was shown in the energy balance, heat production and activity. The strong response of the caged birds to the temperature changes is most probably due to less possibilities for heat dissipation in cages, but also related to larger body weight at the start of the experiment.

\section{Introduction}

High ambient temperatures have a detrimental effect on egg production. In general this effect occurs above $30^{\circ} \mathrm{C}$ even with an adequate composition of the feed (Payne, 1966; Mowbray \& Sykes, 1971). According to Scheele \& Musharaf (1978) and Sykes (1979) this effect is associated with a reduced energy balance.

Apart from the effect of ambient temperature on energy metabolism also housing systems may influence metabolic rate. Ketelaars et al. (1985) found that maintenance requirements of laying hens at $20^{\circ} \mathrm{C}$ and housed in cages was lower than that of hens housed in a group on a wire floor. Furthermore it has been found (Arets, 1981) that the increased heat production from the hens in the wire floor was associated with activity in both housing systems. It may be expected that lower maintenance of hens in cages may be beneficial at high temperature. On the other hand the inability to change the distance from the hens may possibly limit the sensible heat exchange from the birds. In order to test which housing system (cages or wire floor) is most detrimental to the animals at high temperature an experiment was performed in which the effect of rapid changing ambient temperatures on metabolic rate and performance of laying hens was tested. 


\begin{tabular}{|c|c|c|c|c|c|c|c|c|c|c|}
\hline Age $($ tiays $)$ & 302 & 305 & 308 & 311 & 314 & 317 & 320 & 323 & 326 & 329 \\
\hline Temperature $1^{\circ} \mathrm{C}$ & 20 & 23 & 26 & 29 & 32 & 32 & 29 & 26 & 23 & 20 \\
\hline Balance perıods ( $\Psi^{\prime}$ wereghrng) & $\Psi$ & & & & & & & & & \\
\hline Respiration measurements & $X$ & $\boldsymbol{X}$ & $X$ & $X$ & $X$ & $\boldsymbol{X}$ & $X$ & $x$ & $\lambda$ & $x$ \\
\hline
\end{tabular}

Fig. 1. Experimental design.

\section{Material and methods}

Two groups of medium type (Warren SSL) laying hens were housed in two large climate respiration chambers: one with 24 flat-deck laying cages and one with a wire floor system. Cages were $48.5 \mathrm{~cm} \times 45.5 \mathrm{~cm}$. In each cage 4 birds were housed, so space per bird was $552 \mathrm{~cm}^{2}$. The floor system department was divided into 2 pens of approximately $2.5 \mathrm{~m} \times 2.5 \mathrm{~m}$. In each pen 47 birds were housed, so available space was $1330 \mathrm{~m}^{2}$ per hen. At the start of the experiment the hens were 43 weeks of age. The respiration chambers have been described elsewhere by Verstegen et al. (1985).

The experimental period was divided into 10 periods of 3 days each. In 5 successive periods, each of 3 days, the ambient temperature in both chambers was increased in stepwise fashion with $3{ }^{\circ} \mathrm{C}$ in each period starting from $20^{\circ} \mathrm{C}$ and ending at $32^{\circ} \mathrm{C}$ at period 5 . In the following 3-day periods the temperature was changed in the same stepwise fashion from $32^{\circ} \mathrm{C}$ to $20^{\circ} \mathrm{C}$. At the same time the relative humidity (RH) dropped from about $70 \%$ to about $50 \%$ at $32{ }^{\circ} \mathrm{C}$ and back to $70 \%$ at $20^{\circ} \mathrm{C}$. This procedure was chosen to simulate practical conditions and thus avoid a long period of acclimation to each temperature. However each period was long enough to be able to measure energy balance traits.

The performance of the hens was measured in both systems by recording egg production, egg weight and egg shell percentage, feed consumption, body weight and mortality. Furthermore energy balance and respiration measurements were carried out during each 3-day period (Fig. 1). The activity of the birds was measured with an activity meter based on the principle of the Doppler effect (Wenk \& van Es, 1976). Activity was measured as $\mu_{\mathrm{v}}$ per 6-minute period and results are expressed in relation to the measurements at $20^{\circ} \mathrm{C}$. Data of hens in both systems were compared with the t-test, also changes within one group were tested similarly.

\section{Results and discussion}

Before the start of this experiment the hens were kept for 15 weeks (18 to 43 weeks of age) in the respiration chambers at a constant temperature of $20^{\circ} \mathrm{C}$. In this preliminary period the production per hen day was about the same for both housing systems but tended to be somewhat higher in the cages. Egg weight was significantly higher in the cages. With increasing temperatures egg production, egg weight and body weight of the caged hens dropped significantly together with a sharp de- 
HIGH AMBIENT ROOM TEMPERATURES AND METABOLIC RATE AND PERFORMANCE IN HENS

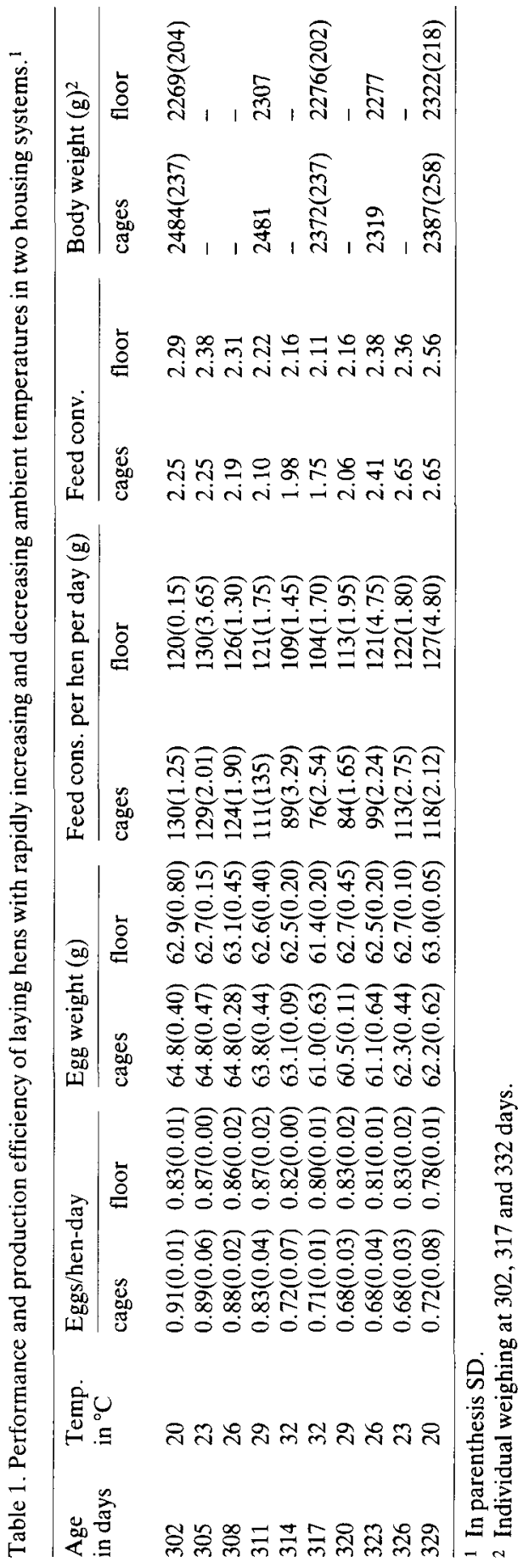

Neth. J. agric. Sci. 33 (1985) 


\section{E. H. KETELAARS ET AL.}

crease in feed consumption (Table 1). The floor hens, however, hardly showed a decrease in production beyond what could be expected as a result of the normal pattern. Egg weight which normally increases with the normal production curve decreased at the high temperature level but recovered fairly soon. The feed consumption of the floor hens showed the normal reaction in decreasing with rising temperature and increasing with lowering temperatures. The response of the caged hens was very pronounced. The feed conversion was initially lower in the cage system together with a very low production and increased rapidly at the end of the experiment as a result of the increased feed consumption which was accompanied by an increased laying rate. The caged hens, initially heavier, lost much weight during the experiment and ended eventually at about the same weight as that of the floor hens. Egg shell percentage dropped with increasing temperature in both systems but again much more in the cages. Mortality did not occur except for one bird in the cage system.

The effect of high temperatures on the performance of laying hens in general (Deaton, 1983) and on egg quality (Ahvar et al., 1982) is well known. A difference in response to high temperature in relation to the housing system is not well known.

Table 2. Egg shell, as a percentage of total egg weight, at rapidly increasing and decreasing ambient temperatures in two housing systems.

\begin{tabular}{|c|c|c|c|}
\hline Age & Temp. & Egg sh & age \\
\hline in days & & cages & floor \\
\hline 304 & 20 & 8.9 & 8.4 \\
\hline 307 & 23 & 8.5 & 9.0 \\
\hline 310 & 26 & 8.4 & 8.9 \\
\hline 313 & 29 & 8.0 & 8.5 \\
\hline 316 & 32 & 7.6 & 8.2 \\
\hline 319 & 32 & 7.3 & 8.1 \\
\hline 322 & 29 & 7.8 & 8.4 \\
\hline 325 & 26 & 8.4 & 8.5 \\
\hline 328 & 23 & 8.8 & 9.0 \\
\hline 331 & 20 & 9.1 & 8.5 \\
\hline 334 & 20 & 9.0 & 8.7 \\
\hline
\end{tabular}

Table 3. Energy balance as affected by changes in ambient temperature in laying hens in two housing systems.

\begin{tabular}{|c|c|c|c|c|c|c|c|c|c|}
\hline \multirow{2}{*}{$\begin{array}{l}\text { Age } \\
\text { in days }\end{array}$} & \multirow{2}{*}{$\begin{array}{l}\text { Temp. } \\
\text { in }{ }^{\circ} \mathrm{C}\end{array}$} & \multicolumn{2}{|c|}{ ME intake } & \multicolumn{2}{|c|}{ Heat production } & \multicolumn{2}{|c|}{ Egg energy } & \multicolumn{2}{|c|}{ Energy balance* } \\
\hline & & cage & floor & cage & floor & cage & floor & cage & floor \\
\hline 302 & 20 & 816 & 859 & 590 & 619 & 252 & 254 & -26 & -14 \\
\hline 311 & $26-29$ & 631 & 770 & 517 & 577 & 213 & 248 & -99 & -55 \\
\hline 317 & 32 & 498 & 717 & 455 & 546 & 186 & 234 & -143 & -63 \\
\hline 326 & $26-23$ & 722 & 844 & 535 & 590 & 197 & 227 & -10 & 27 \\
\hline
\end{tabular}

* In kJ d-1 $\mathrm{kg}^{-0.75}$. 
Table 4. Activity of laying hens, in two housing systems, as affected by changes in ambient temperature.

\begin{tabular}{lllr}
\hline Age in days & Temperature in ${ }^{\circ} \mathrm{C}$ & \multicolumn{2}{l}{ Activity* } \\
\cline { 3 - 4 } & & cages & floor \\
302 & 20 & 100 & 100 \\
305 & 23 & 92 & 93 \\
308 & 26 & 87 & 86 \\
311 & 29 & 84 & 87 \\
314 & 32 & 69 & 86 \\
317 & 32 & 78 & 91 \\
320 & 32 & 63 & 91 \\
323 & 29 & 84 & 114 \\
326 & 23 & 91 & 102 \\
329 & 20 & 86 & 101 \\
\hline
\end{tabular}

* Activity in the first period $=100$.

The observed difference in response can be explained by the different reactions which take place in the energy balance of the hens in the respective housing systems (Sykes, 1979). Intake of metabolizable energy (ME) decreased with rising temperature in both systems. Data in Table 3 clearly indicate that in the cage system ME intake fell by $133 \mathrm{~kJ}$ ME when temperature rose from $26-29$ to $32{ }^{\circ} \mathrm{C}$. Heat production, however, was only reduced by $62 \mathrm{~kJ} \mathrm{ME}$ at $32{ }^{\circ} \mathrm{C}$. This indicates that heat production at $32{ }^{\circ} \mathrm{C}$ relatively increased. Therefore energy output in eggs and energy retained was reduced extra because reducing heat production did not follow the reduction in ME intake. In the floor system ME intake fell by only $53 \mathrm{~kJ}$ and heat production by $31 \mathrm{~kJ}$. Thus the cage system seemed to cause more heat stress to the hens at $32{ }^{\circ} \mathrm{C}$ than the floor system did. However it needs to be pointed out that the cage hens were heavier at the start and therefore probably more susceptible to heat stress. This is undoubtedly related to the less favourable body value ratio of the hens. Therefore the effect was much more pronounced with the animals in the cages so that the differences between the two systems increased further with increasing temperatures. Both the housing systems, as well as the temperature levels, had a significant $P<0.005$ ) effect on the energy balance.

The relative activity of the birds decreased with increasing temperature and increased again with decreasing temperatures as could be expected (Table 4), the effect being again much more pronounced with the animals in the cage system.

Acclimation however may occur when birds are exposed to a higher ambient temperature for a prolonged time (Sykes, 1979), although initially the situation may even grow worse. Under conditions of the present experiment the effect of a short period of heat stress on laying hens appeared to be more pronounced in the cage system. This result is most probably due to reduced possibilities for heat dissipation in cages compared to the wire floor conditions. It should be emphasized that results obtained in this experiment may be different after a long-time exposure to each temperature. The present experiment was designed to measure effects of exposure after a few days. 


\section{E. H. KETELAARS ET AL.}

\section{References}

Ahvar, F., J. Petersen, P. Horst \& H. Thein, 1982. Veränderungen der Eibeschaffenheit in der 1. Legeperiode under dem Einfluss hoher Umwelttemperaturen. Archiv für Geflügelkunde 46: 1-8.

Arets, W. L. M., 1981. Vergelijking van twee huisvestingssystemen van leghennen met behulp van respiratiemetingen in klimaatcellen. Student thesis, Agricultural University, Wageningen.

Deaton, J. W., 1983. Alleviation of heat stress for avian egg production - a review. World's Poultry Science Journal 39: 210-217.

Ketelaars, E. H., W. L. M. Arets, W. van der Hel, A. J. Wilbrink \& M. W. A. Verstegen, 1985. Effect of housing systems on the energy balance of laying hens. Netherlands Journal of Agricultural Science 33: $35-43$.

Mowbray, R. M. \& A. H. Sykes, 1971. Egg production in warm environmental temperatures. British Poultry Science 12: 25-29.

Payne, C. G., 1966. Practical aspects of environmental temperature for laying hens. World's Poultry Science Journal 22: 126-139.

Scheele, C. W. \& N. A. Musharaf, 1978. Balance experiments with laying hens at high environmental temperature. Reports 188-78, 189-78. Poultry Research Institute 'Spelderholt', Beekbergen, Netherlands.

Sykes, A. H., 1979. Environmental temperature and energy balance in the laying hen. In: K. N. Boorman \& B. M. Freeman (Eds.), Food intake regulation in poultry, p. 207-229. British Poultry Science Ltd., Edinburgh.

Verstegen, M. W. A. et al., Indirect calorimetry with larger groups of animals. (In preparation.).

Wenk, C. \& A. J. H. van Es, 1976. Eine Methode zur Bestimmung des Energieaufwandes für körperliche Aktivität von wachsende Küken. Schweizerische Landwirtschaftliche Monathefte 54: 232-236.

Wilbrink, A. J., 1982. Vergelijking van twee huisvestingssystemen voor leghennen, m.b.t. fysiologische en produktiekenmerken. Student thesis, Agricultural University, Wageningen. 